\title{
In situ autonomous optical radiometry measurements for satellite ocean color validation in the Western Black Sea
}

\author{
G. Zibordi, F. Mélin, J.-F. Berthon, and M. Talone \\ European Commission, Joint Research Centre, Ispra, Italy \\ Correspondence to: G. Zibordi (giuseppe.zibordi@jrc.ec.europa.eu)
}

Received: 4 November 2014 - Published in Ocean Sci. Discuss.: 20 December 2014

Revised: 15 February 2015 - Accepted: 3 March 2015 - Published: 26 March 2015

\begin{abstract}
The accuracy of primary satellite ocean color data products from the Moderate Resolution Imaging Spectroradiometer on-board Aqua (MODIS-A) and the Visible/Infrared Imager/Radiometer Suite (VIIRS) is investigated in the Western Black Sea using in situ measurements from the Gloria site included in the ocean color component of the Aerosol Robotic Network (AERONET-OC). The analysis is also extended to an additional well-established AERONET-OC site in the northern Adriatic Sea characterized by optically complex coastal waters exhibiting similarities to those observed at the Gloria site. Results from the comparison of normalized water-leaving radiance $L_{\mathrm{WN}}$ indicate biases of a few percent between satellite-derived and in situ data at the center wavelengths relevant for the determination of chlorophyll $a$ concentrations $(443-547 \mathrm{~nm}$, or equivalent). Remarkable is the consistency between the annual cycle determined with time series of satellite-derived and in situ $L_{\mathrm{WN}}$ ratios at these center wavelengths. Contrarily, the differences between in situ and satellite-derived $L_{\mathrm{WN}}$ are pronounced at the blue (i.e., $412 \mathrm{~nm}$ ) and red (i.e., $667 \mathrm{~nm}$, or equivalent) center wavelengths, confirming difficulties in confidently applying satellite-derived radiometric data from these spectral regions for quantitative analysis in optically complex waters.
\end{abstract}

\section{Introduction}

During the last decades, satellite ocean color data were applied to biology, biogeochemistry and climate change studies. For instance, time series of chlorophyll $a$ concentration (Chl $a$ ) were shown to be relevant (i) for determining seasonal cycles of phytoplankton biomass and investigating the climate effects on marine ecosystems (Behrenfeld et al., 2006), (ii) quantifying primary production on regional and global scales (Longhurst et al., 1995; Field et al., 1998), (iii) supporting studies on ecological processes (Platt et al., 2003), carbon cycle and air-sea fluxes (Lohrenz and Cai, 2006), and (iv) sustaining fishery services and coastal management (Stumpf, 2001; Ware and Thompson, 2005).

Confidence in remote sensing applications is established by the quality of satellite data products. Because of this, the assessment of satellite data is a major task of any ocean color mission performed by investigating uncertainties in primary (e.g., normalized water-leaving radiance) and derived (e.g., Chl $a$ ) data products through in situ reference data representative of the variety of observation conditions offered by the world seas. This is pursued by combining in situ data from different and often independent sources. However, data sets constructed following such a scheme are affected by overall uncertainties difficult to quantify because of the use of different instruments, measurement protocols, processing and quality assurance schemes. Thus, standardization of measurements through the application of identical instruments, measurement protocols, processing and quality assurance schemes, is certainly a viable solution to increase consistency of data sets and make them more applicable to the assessment of satellite data products.

By embracing such a measurement concept, the ocean color component of the Aerosol Robotic Network (AERONET-OC) allows the generation of standardized data relevant for the assessment of primary satellite ocean color products (i.e., spectral normalized water-leaving radiance $L_{\mathrm{WN}}$ and aerosol optical thickness $\tau_{\mathrm{a}}$ ) in coastal regions (Zibordi et al., 2009b). 
This work presents and discusses AERONET-OC optical radiometric data collected at the Gloria site (hereafter GLR) in the Western Black Sea to support satellite ocean color validation activities. Specifically, after a brief introduction to the bio-optical properties of the region and to the in situ measurements from the GLR site, the study focuses on the assessment of satellite primary data products from the Moderate Resolution Imaging Spectroradiometer onboard the Aqua platform (MODIS-A) launched in May 2002 and from the Visible/Infrared Imager/Radiometer Suite (VIIRS) onboard the Suomi National Polar-orbiting Partnership (NPP) launched in October 2011. The assessment is also extended to the AERONET-OC Acqua Alta Oceanographic Tower site (hereafter AAOT) established in the northern Adriatic Sea in 2002. In fact, the long data record and the large bio-optical variability characterizing the AAOT site provide a term of reference to comprehensively evaluate and discuss GLR results.

\section{The measurement site}

The Black Sea receives drainage from almost one-third of continental Europe through the Danube, Dniester and Dnieper rivers. The nutrients injected into the basin by these northwestern rivers and the small water exchange with the Mediterranean Sea through the Bosphorus Strait have strongly influenced the Black Sea bio-geochemical processes during the last decades (e.g., Kideys, 2002; Oguz, 2005). The severe environmental degradation of the basin, with almost $90 \%$ of its volume affected by serious anthropogenic pressure, has triggered the need for extended regional investigations. However, the use of satellite ocean color imagery to perform bio-geochemical investigations in the Black Sea has been hindered by the limited statistical representativity of bio-optical algorithms, based on a small number of in situ measurements and applied for the generation of high-level satellite data products (Kopelevich et al., 2004; Sancak et al., 2005).

In view of supporting a better exploitation of satellite ocean color data in the Black Sea, since 2006 a number of dedicated bio-optical oceanographic campaigns have been performed on the western side of the basin (Zibordi et al., 2011) with the objective of contributing to bio-optical modeling and validation activities (D'Alimonte et al., 2012, 2014; Zibordi et al., 2013). Complementary to ship measurements, in late 2010 an AERONET-OC site was established on the Romanian Shelf southeast of the Danube plume (long. $29.360^{\circ} \mathrm{E}$ and lat. $44.600^{\circ} \mathrm{N}$ ) to create time series of in situ reference data for continuous validation of satellite ocean color products.

The site, operated in collaboration with the Grigore Antipa National Institute for Marine Research and Development in Constanta, relies on the Gloria platform owned and managed by the Petrom oil company. Due to its location in the northwestern Shelf region (see Fig. 1), GLR contributes to
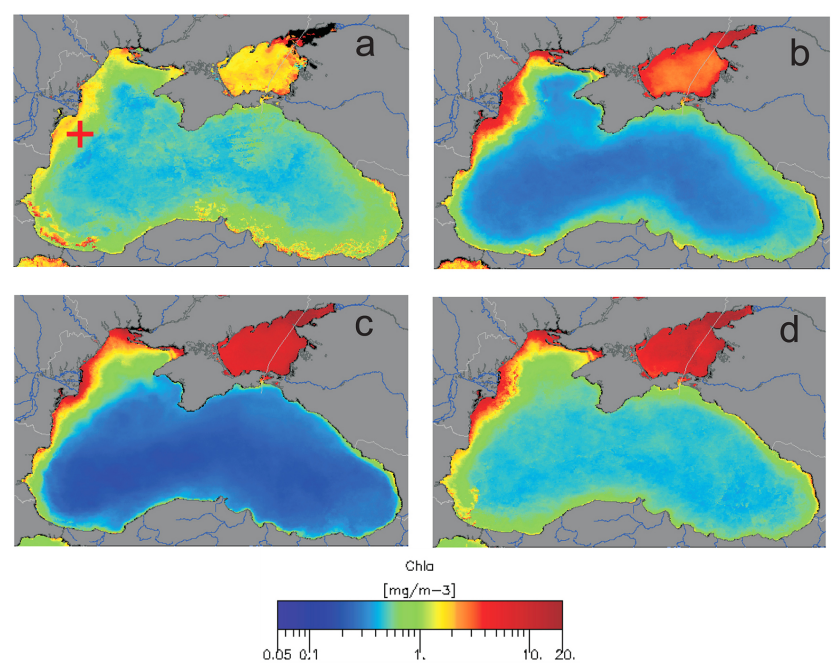

Figure 1. Monthly climatology maps of Chl $a$ for the Black Sea (a January; b April; c July; d October) obtained from the application of a regional bio-optical algorithm (see Sect. 3.3 for details) applied to MODIS-A data. The red symbol "+" in panel (a) indicates the location of GLR.

AERONET-OC globally distributed measurements, with data generally representing water moderately dominated by sediments and colored dissolved organic matter. However, it is expected that the site may occasionally exhibit unique concentrations of coccolithophores during the summer season and high sediment concentration during seasons affected by high runoff from the Danube.

The Chl $a$ climatology of the Black Sea is illustrated in Fig. 1 through maps constructed with MODIS-A data from 2002 to 2010 for the months of January, April, July and October. Chl $a$ values clearly indicate different bio-optical regimes for the western Shelf and the open sea regions. In particular, in agreement with previous in situ measurements and satellite observations (Vinogradov et al., 1999; Sorokin, 2002; Kopelevich et al., 2004; McQuatters-Gollop et al., 2008), Chl $a$ concentrations exhibit the highest values during winter in the open Black Sea regions, while on the western Shelf, they show maxima pronounced in late spring-summer and less marked in fall.

Typical values of quantities characterizing optically significant constituents for the Western Black Sea waters, which refer to in situ data collected within the framework of the Bio-Optical mapping of Marine Properties (BiOMaP) measurement program (Zibordi et al., 2011), are summarized in Table 1. These values have been determined using measurements from 316 stations performed during eight oceanographic cruises from 2006 to 2012. The large standard deviation characterizing $\mathrm{Chl} a$ is an index of the large variability affecting the western basin. 
Table 1. Median (Med), mean (Avg) and standard deviation (SD) values of optical properties, concentration of constituents and salinity of the Western Black Sea surface waters (specifically: absorption coefficients of pigmented particles, $a_{\mathrm{ph}}$, non-pigmented particles, $a_{\mathrm{dp}}$, and colored dissolved organic matter, $a_{y}$, at $443 \mathrm{~nm}$; backscattering coefficient of particles, $b_{\mathrm{bp}}$, at $443 \mathrm{~nm}$; diffuse attenuation coefficient, $K_{\mathrm{d}}$, at $490 \mathrm{~nm}$; concentration of total suspended matter, TSM, and chlorophyll $a$, Chl $a$; and salinity, $S_{\mathrm{W}}$ ).

\begin{tabular}{lcccccccc}
\hline Quantity & $\begin{array}{c}a_{\mathrm{ph}}(443) \\
\left(\mathrm{m}^{-1}\right)\end{array}$ & $\begin{array}{c}a_{\mathrm{dp}}(443) \\
\left(\mathrm{m}^{-1}\right)\end{array}$ & $\begin{array}{c}a_{y}(443) \\
\left(\mathrm{m}^{-1}\right)\end{array}$ & $\begin{array}{c}b_{\mathrm{bp}}(443) \\
\left(\mathrm{m}^{-1}\right)\end{array}$ & $\begin{array}{c}K_{\mathrm{d}}(490) \\
\left(\mathrm{m}^{-1}\right)\end{array}$ & $\begin{array}{c}\mathrm{TSM} \\
\left(\mathrm{g} \mathrm{m}^{-3}\right)\end{array}$ & $\begin{array}{c}\text { Chl } a \\
\left(\mathrm{mg} \mathrm{m}^{-3}\right)\end{array}$ & $\begin{array}{c}S_{\mathrm{w}} \\
(\mathrm{psu})\end{array}$ \\
\hline Med & 0.028 & 0.018 & 0.106 & 0.0078 & 0.116 & 0.52 & 0.41 & 17.01 \\
Avg & 0.084 & 0.026 & 0.129 & 0.0125 & 0.185 & 0.94 & 1.38 & 16.05 \\
SD & 0.132 & 0.026 & 0.071 & 0.0090 & 0.204 & 0.92 & 2.57 & 4.47 \\
\hline
\end{tabular}

\section{Assessment of satellite data products}

The application of GLR data and those from the Acqua Alta Oceanographic Tower (AAOT) to the assessment of satellite ocean color primary products is proposed in the following sections. In view of providing the basis for such an assessment, in situ and satellite data, the criteria applied for the construction of match-ups (i.e., pair of in situ and satellite data) and the methodology used for the analysis are briefly introduced in the following subsections.

\subsection{In situ AERONET-OC data}

AERONET-OC aims at delivering standardized in situ $L_{\mathrm{WN}}$ (Zibordi et al., 2009b) and $\tau_{\mathrm{a}}$ (Smirnov et al., 2000; Holben et al., 1998) through (i) the use of identical instruments and of a unique measurement protocol; (ii) the calibration of network radiometers by applying a sole method and laboratory; and, finally, (iii) the reduction and quality control of measurements by using a single processing code.

It is reminded that the processing and quality control are performed in agreement with the scheme presented in $\mathrm{Zi}-$ bordi et al. (2009a). This implies the correction of the effects of non-isotropy of the in-water light field and surface reflectance following the method proposed by Morel et al. (2002). It is recognized that this method, which was proposed for $\mathrm{Chl} a$ dominated waters, is certainly challenged in coastal regions. Nevertheless, the related uncertainties are accounted for in the uncertainty budget for $L_{\mathrm{WN}}$ (Zibordi et al., 2009b).

Data products determined at different center wavelengths $\lambda$ in the $412-1020 \mathrm{~nm}$ spectral region (nominally, 412, 443, $488,531,551,667,870$ and $1020 \mathrm{~nm}$ ) are available at three levels of quality control: (i) Level 1.0 derived from complete sequences of in situ measurements; (ii) Level $1.5 \mathrm{ob}-$ tained after cloud screening and applying a series of quality tests designed to remove measurements affected by significant environmental perturbations or artifacts; and finally, (iii) Level 2.0, comprising fully quality-controlled data generated after post-deployment calibration and checks of individual data records. Level 1.0 and Level 1.5 data are accessible in almost real time through a web interface. Level 2 data products are only accessible after each deployment pe-
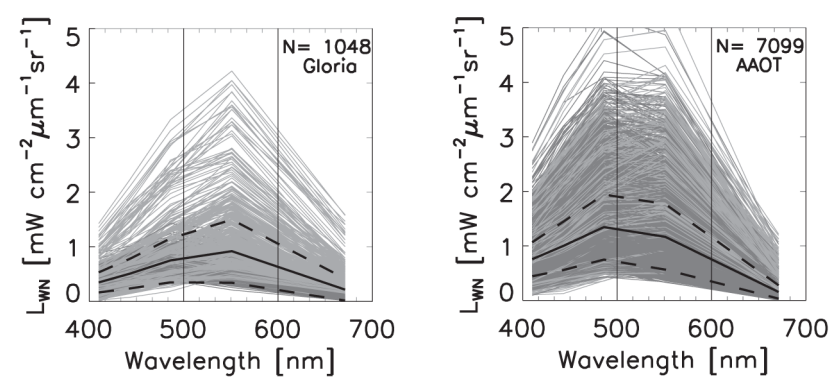

Figure 2. AERONET-OC Level-2 $L_{\mathrm{WN}}$ spectra from the GLR and AAOT sites. The thick black line indicates mean values, while the thick dashed lines indicate \pm 1 standard deviation.

riod lasting approximately 6-12 months. The data analysis included in this study is only based on Level-2 data.

A comprehensive evaluation of uncertainties affecting AERONET-OC $L_{\mathrm{WN}}$ was performed for a number of sites exhibiting a variety of water types and different atmospheric aerosols (Gergely and Zibordi, 2014). In the specific case of the GLR site, results indicate mean relative combined uncertainties of $5-10 \%$ in the $412-667 \mathrm{~nm}$ spectral region. The corresponding absolute combined uncertainties vary from approximately 0.03 to $0.04 \mathrm{~mW} \mathrm{~cm}^{-2} \mu \mathrm{m}^{-1} \mathrm{sr}^{-1}$ between 412 and $551 \mathrm{~nm}$, and exhibit a value of $0.01 \mathrm{~mW} \mathrm{~cm}^{-2} \mu \mathrm{m}^{-1} \mathrm{sr}^{-1}$ at $667 \mathrm{~nm}$. In the case of the AAOT site, the relative combined uncertainties are lower than those determined for GLR data and show values of approximately $5 \%$ between 412 and $551 \mathrm{~nm}$, increasing to $7 \%$ at $667 \mathrm{~nm}$. Conversely, the absolute combined uncertainties are slightly larger for the AAOT data in the $412-551 \mathrm{~nm}$ region, with values varying from 0.04 to $0.06 \mathrm{~mW} \mathrm{~cm}^{-2} \mu \mathrm{m}^{-1} \mathrm{sr}^{-1}$, while the value at $667 \mathrm{~nm}$ is identical (i.e., $0.01 \mathrm{~mW} \mathrm{~cm}^{-2} \mu \mathrm{m}^{-1} \mathrm{sr}^{-1}$ ). These estimated values account for uncertainties due to (i) absolute calibration, (ii) change in instrument sensitivity during field deployment, (iii) corrections for the viewing angle geometry and the anisotropy of water and surface light fields, (iv) variability in the input quantities required to determine $L_{\mathrm{WN}}$ (e.g., wind speed, surface reflectance, and diffuse atmospheric transmittance), and (v) environmental perturbations, which exhibit the largest contribution, due to wave effects and changes 

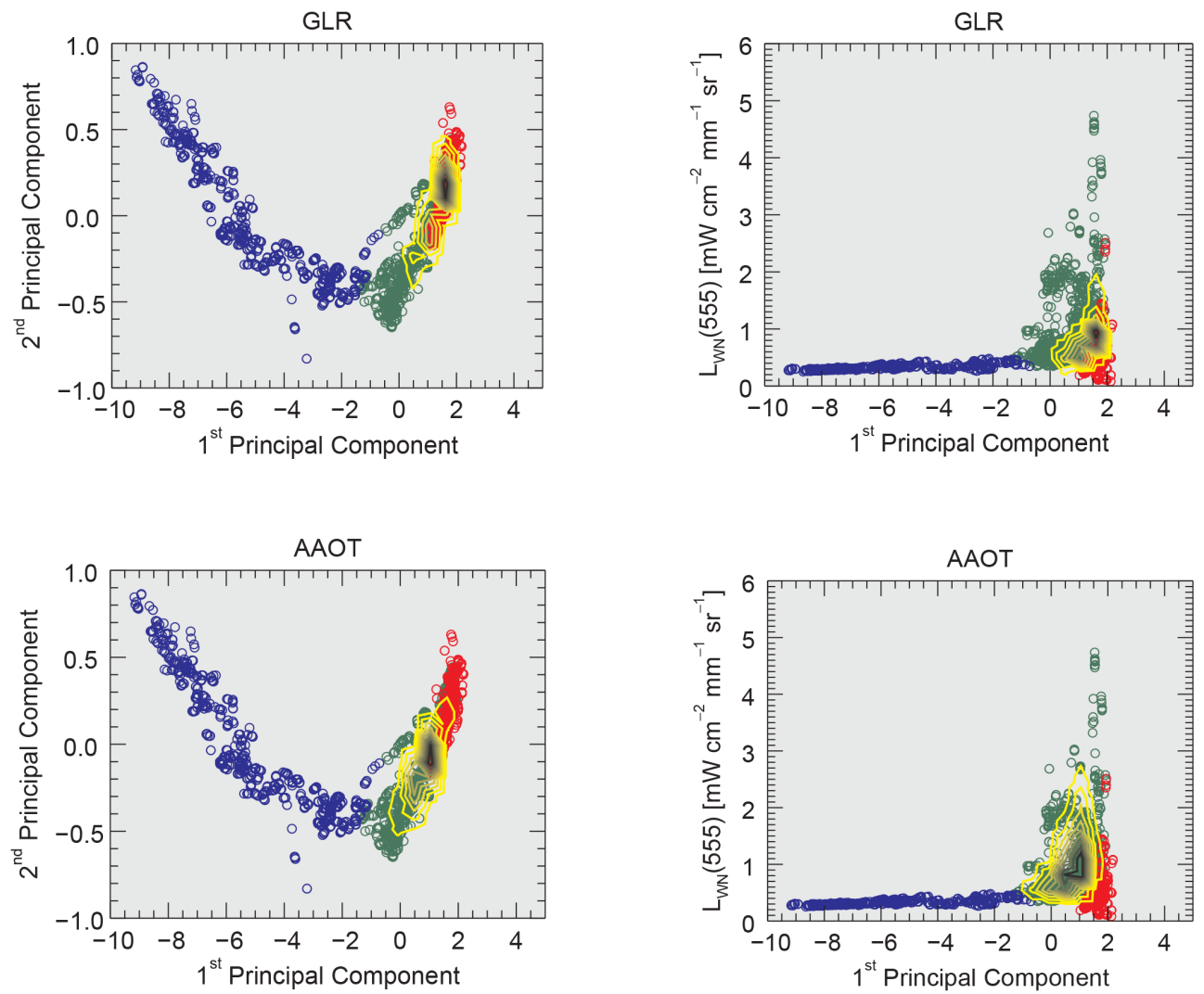

Figure 3. Maps of AERONET-OC $L$ WN spectra from GLR (upper panels) and AAOT (lower panels) with the first two components of PCA applied to $L_{\mathrm{WN}}(\lambda) / L_{\mathrm{WN}}(555)$ (left panels) and $L_{\mathrm{WN}}(555)$ versus the first PCA component (right panels). While the isolines refer to the density distribution of AERONET-OC $L_{\mathrm{WN}}$ from GLR or AAOT sites (indicating $10 \%$ increments from light yellow to black), the circles refer to different water types (see Zibordi et al., 2011): blue for oligotrophic and mesotrophic Chl $a$-dominated waters; red for yellowsubstance-dominated waters; and green for a number of optically complex waters likely expected to be moderately sediment dominated.

in illumination and water masses during measurement sequences. For completeness, it is mentioned that uncertainties in AERONET $\tau_{\mathrm{a}}$ values are lower than \pm 0.02 (Eck et al., 1999).

AERONET-OC spectra from GLR and AAOT reconstructed through band shifting (see Sect. 3.3) to match the MODIS-A center wavelengths are presented in Fig. 2. Notably, GLR spectra exhibit maxima at $547 \mathrm{~nm}$ for $55 \%$ of the cases and at $488 \mathrm{~nm}$ for $29 \%$. In contrast, the AAOT spectra have maxima occurring at $488 \mathrm{~nm}$ for $80 \%$ of the cases and at $547 \mathrm{~nm}$ for $17 \%$ only.

The representativity of the GLR and AAOT $L_{\mathrm{WN}}$ spectra with respect to those from different European water types constituting the BiOMaP data set is evaluated through features indicating shape and amplitude of spectra (Zibordi et al., 2011; D'Alimonte et al., 2012). Specifically, after bandshifting the GLR and AAOT spectra to match the BiOMaP center wavelengths (i.e., 412, 443, 490, 555 and $665 \mathrm{~nm}$; see Sect. 3.3), the spectral shape is represented through the first two components from the principal component analysis (PCA, see Jolliffe, 2002) of spectra normalized to their val- ues at $555 \mathrm{~nm}$ (i.e., $L_{\mathrm{WN}}(\lambda) / L_{\mathrm{WN}}(555)$, with $\lambda=412,443$, 490 and $665 \mathrm{~nm}$ ). The amplitudes of spectra are simply given by the scaling value $L_{\mathrm{WN}}(555)$.

Projections of BiOMaP, GLR and AAOT $L_{\mathrm{WN}}$ spectra are displayed in Fig. 3. Circles indicate the projection of single BiOMaP spectra and the axes correspond to the projective directions (i.e., the first two components of PCA, and $\left.L_{\mathrm{WN}}(555)\right)$. On the basis of a priori knowledge of regional water types, the blue, red, and green circles indicate oligotrophic and mesotrophic $\mathrm{Chl} a$-dominated waters, yellow-substance-dominated waters, and moderately sediment-dominated waters, respectively. GLR and AAOT data are presented through contour plots from density distributions of projected spectra superimposed onto the BiOMaP values. Specifically, the GLR and AAOT $L_{\mathrm{WN}}$ projected spectra have been mapped to a uniform grid and the contour lines have then been constructed from the number of occurrences of the grid cells. Each line in Fig. 3 represents a $10 \%$ increment with values varying from $10 \%$ (light yellow) to the maximum value of occurrences (black). 
As already evident from the similarities shown by the spectra in Fig. 2, the GLR and AAOT data mapped in Fig. 3 exhibit large areas of overlapping. Ultimately, both GLR and AAOT $L_{\mathrm{WN}}$ spectra represent optically complex waters, with GLR data exhibiting a large number of cases overlapping with the Baltic Sea water dominated by colored dissolved organic matter (see the density distribution of the darkest isolines in Fig. 3).

\subsection{Satellite data}

Match-ups for the GLR and AAOT sites were constructed using MODIS-A data acquired from the Goddard Space Flight Center (GSFC) of the National Aeronautics and Space Administration (NASA) and processed with the SeaWiFS Data Analysis System (SeaDAS) software package version 7.0 (Fu et al., 1998; Gordon and Wang, 1994; Wang et al., 2005). In contrast, the VIIRS data were acquired as Level-2 files from GSFC (identified as R2014.0 reprocessing). Consistent with AERONET-OC data, MODIS-A $L_{\mathrm{WN}}$ remote sensing data products at the $412,443,488,531,547$ and $667 \mathrm{~nm}$ center wavelengths, and VIIRS data at 410, 443, 486, 551, $671 \mathrm{~nm}$, are corrected for bi-directional effects by applying the same scheme.

\subsection{Band-shift correction and regional algorithms}

Comparisons of in situ and satellite $L_{\mathrm{WN}}$ may be affected by differences in center wavelengths between sensors. This potential source of uncertainty is minimized through the application of specific adjustment factors to the in situ $L_{\mathrm{WN}}$ (i.e., band-shift correction) in agreement with the scheme outlined by Zibordi et al. (2006), Mélin and Zibordi (2007) and Zibordi et al. (2009a).

In summary, the synthetic value $L_{\mathrm{WN}}(\lambda)$ at the centerwavelength $\lambda$ is determined from the actual $L_{\mathrm{WN}}\left(\lambda_{0}\right)$ at a near center-wavelength $\lambda_{0}$ assuming ideal $10 \mathrm{~nm}$ wide spectral bandwidths, from

$L_{\mathrm{WN}}(\lambda)=L_{\mathrm{WN}}\left(\lambda_{0}\right) \frac{E_{0}(\lambda)}{E_{0}\left(\lambda_{0}\right)} \frac{b_{\mathrm{b}}(\lambda)}{a(\lambda)+b_{\mathrm{b}}(\lambda)} \frac{a\left(\lambda_{0}\right)+b_{\mathrm{b}}\left(\lambda_{0}\right)}{b_{\mathrm{b}}\left(\lambda_{0}\right)}$,

where $E_{0}(\lambda)$ is the extra-atmospheric solar irradiance (Thuillier et al., 2003), $a(\lambda)$ the total water absorption coefficient and $b_{\mathrm{b}}(\lambda)$ the total backscattering coefficient. It is recalled that $a(\lambda)$ is given by the sum of contributions due to particulate matter, $a_{\mathrm{p}}(\lambda)$ (separated into contributions by pigmented, $a_{\mathrm{ph}}(\lambda)$, and non-pigmented, $a_{\mathrm{dp}}(\lambda)$, particles), colored dissolved organic matter, $a_{y}(\lambda)$, and pure seawater, $a_{\mathrm{w}}(\lambda)$. The value of $b_{\mathrm{b}}(\lambda)$ is given by the sum of the backscattering coefficients of particulate matter, $b_{\mathrm{bp}}(\lambda)$, and of pure seawater, $b_{\mathrm{bw}}(\lambda)$.

The relevant spectral input quantities defining $a(\lambda)$ and $b_{\mathrm{b}}(\lambda)$, excluding $a_{\mathrm{w}}(\lambda)$ and $b_{\mathrm{bw}}(\lambda)$, which are known, are iteratively determined using regional algorithms relying on the logarithm of remote sensing reflectance ratios

$R_{\mathrm{rs}}\left(\lambda_{i}, \lambda_{j}\right)=\log _{10}\left[R_{\mathrm{rs}}\left(\lambda_{i}\right) / R_{\mathrm{rs}}\left(\lambda_{j}\right)\right]$,

where the remote sensing reflectance $R_{\mathrm{rs}}(\lambda)$ (with $\lambda=\lambda_{i}$, $\lambda_{j}$ ) is determined from AERONET-OC $L_{\mathrm{WN}}(\lambda)$ with

$R_{\mathrm{rS}}(\lambda)=L_{\mathrm{WN}}(\lambda) / E_{0}(\lambda)$.

While site-specific algorithms were already provided for the AAOT in a different work (Zibordi et al., 2009a), regional algorithms applicable to GLR data have been developed using in situ BiOMaP data from the Western Black Sea. By bandshifting BiOMaP data, algorithms are proposed for both the MODIS-A center wavelengths and, consistent with previous investigations (see Zibordi et al., 2009a), also for the Sea-Viewing Wide Field-of-View Sensor (SeaWiFS) center wavelengths (i.e., 412, 443, 490, 510, 555 and $670 \mathrm{~nm}$ ).

Following Morel and Maritorena (2001), the spectral values of $a_{\mathrm{ph}}(\lambda)$ are estimated from

$a_{\mathrm{ph}}(\lambda)=0.06 a_{\mathrm{c}}(\lambda) \operatorname{Chl} a^{0.65}$,

where $a_{\mathrm{c}}(\lambda)$ is the Chl $a$-specific absorption coefficient (Prieur and Sathyendranath, 1981) and Chl $a$ is computed from

$$
\begin{aligned}
\log _{10}(\mathrm{Chl} a) & =-0.0436-2.7236 R_{\mathrm{rS}}(488,547) \\
& +1.2278 R_{\mathrm{rs}}^{2}(488,547)-3.6611 R_{\mathrm{rs}}^{3}(488,547),
\end{aligned}
$$

with coefficients derived from the regression of in situ Chl $a$ and $R_{\mathrm{rs}}(488,547)$ ratios with determination coefficient $r^{2}=$ 0.88 and number of samples $N=316$. The corresponding coefficients for $R_{\mathrm{rs}}(490,555)$ are $-0.0067,-2.6815$, +1.2318 and -3.2713 , with $r^{2}$ and number of samples $N$ identical to the MODIS-A case (a condition that equally applies to the following algorithms). Equation (5) has been applied to MODIS-A $R_{\mathrm{rS}}(\lambda)$ for the determination of the Chl $a$ maps presented in Fig. 1.

The estimate of $a_{\mathrm{dp}}(\lambda)$ is made through (Yentsch, 1962; Kirk, 1980)

$a_{\mathrm{dp}}(\lambda)=a_{\mathrm{dp}}(412) \exp \left[-S_{\mathrm{dp}} \cdot(\lambda-412)\right]$,

where $S_{\mathrm{dp}}=0.011 \mathrm{~nm}^{-1}$ (Berthon et al., 2008), and

$$
\begin{aligned}
\log _{10} a_{\mathrm{dp}}(412) & =-0.6942-1.2616 R_{\mathrm{rs}}(488,667) \\
& +0.2749 R_{\mathrm{rs}}^{2}(488,667),
\end{aligned}
$$

with coefficients determined from the regression of in situ $a_{\mathrm{dp}}(412)$ and $R_{\mathrm{rs}}(488,667)$ ratios with $r^{2}=0.74$ and $N=$ 316. The corresponding coefficients for $R_{\mathrm{rs}}(490,670)$ are $-0.6930,-1.2501$ and +0.2672 .

Spectral values of $a_{y}(\lambda)$ are estimated using

$a_{y}(\lambda)=a_{y}(400) \exp \left[-S_{y} \cdot(\lambda-400)\right]$, 
where $S_{y}=0.016 \mathrm{~nm}^{-1}$ (Berthon et al., 2008), and

$$
\begin{aligned}
\log _{10} a_{y}(400) & =-0.756-0.7429 R_{\mathrm{rs}}(412,547) \\
& +0.4984 R_{\mathrm{rs}}^{2}(412,547)
\end{aligned}
$$

with coefficients derived from the regression of in situ $a_{y}(400)$ and $R_{\mathrm{rs}}(412,547)$ ratio data with $r^{2}=0.66$ and $N=$ 316. The corresponding coefficients for $R_{\mathrm{rs}}(412,555)$ are $-0.7435,-0.7379$ and +0.4468 .

Spectral values of $b_{\mathrm{bp}}(\lambda)$ are estimated with

$b_{\mathrm{bp}}(\lambda)=b_{\mathrm{bp}}(510) \cdot(\lambda / 510)^{-S_{\mathrm{bp}}}$,

where $S_{\mathrm{bp}}=1.3$ (Berthon et al., 2008), and

$$
\begin{aligned}
\log _{10} b_{\mathrm{bp}}(510) & =-2.1519-1.8363 R_{\mathrm{rs}}(488,547) \\
& +1.727 R_{\mathrm{rs}}^{2}(488,547),
\end{aligned}
$$

with coefficients derived from the regression of in situ $b_{\text {bp }}(510)$ and $R_{\mathrm{rs}}(488,547)$ ratios with $r^{2}=0.70$ and $N=$ 316. The corresponding coefficients for $R_{\mathrm{rs}}(490,555)$ are $-2.1243,-1.8166$, and +1.5001 .

Uncertainties in the applied band-shift correction vary with the spectral region of interest, the spectral distance between the target wavelength $\lambda$ and the actual wavelength $\lambda_{0}$ for which the measurement is available (which generally slightly differs from the nominal center wavelength and may vary from instrument to instrument), and, additionally, the uncertainties in the algorithms applied for the determination of $a(\lambda)$ and $b_{\mathrm{b}}(\lambda)$. In the specific case of MODISA match-ups, the largest mean corrections applied to GLR AERONET-OC data are of $+3.2 \%$ at $443 \mathrm{~nm},-1.8 \%$ at $488 \mathrm{~nm},+1.4 \%$ at $547 \mathrm{~nm}$ and $+1.2 \%$ at $667 \mathrm{~nm}$. In the case of VIIRS match-ups, the largest mean corrections are of $-1.7 \%$ at $440 \mathrm{~nm},+2.4 \%$ at $443 \mathrm{~nm},-1.8 \%$ at $486 \mathrm{~nm}$ and $-1.3 \%$ at $671 \mathrm{~nm}$. The uncertainties in the band-shift corrections are likely to be much smaller than the correction values and thus are assumed to not significantly affect the uncertainty in the corrected data with respect to the original input AERONET-OC data.

\subsection{Match-up analysis}

The comparison of primary satellite and in situ products $\mathfrak{I}$ (i.e., $L_{\mathrm{WN}}$ or $\tau_{\mathrm{a}}$ ) is presented through the average of percent differences, $\psi$, and the average of the absolute percent differences, $|\psi|$, of $N$ match-ups.

The values of $\psi$ are computed through

$\psi=\frac{1}{N} \sum_{i=1}^{N} \psi_{i}$,

where $i$ is the match-up index, and $\psi_{i}$ is

$\psi_{i}=100 \frac{\Im^{\mathrm{SAT}}(i)-\Im^{\mathrm{PRS}}(i)}{\Im^{\mathrm{PRS}}(i)}$, with $\Im^{\mathrm{SAT}}$ indicating the quantities computed from satellite observations, and $\Im^{\mathrm{PRS}}$ the reference Level-2 AERONET-OC data assumed to have uncertainties much smaller than those affecting the satellite data. The absolute values $\left|\psi_{i}\right|$ are used to compute $|\psi|$ according to

$|\psi|=\frac{1}{N} \sum_{i=1}^{N}\left|\psi_{i}\right|$.

The statistical indices $\psi$ and $|\psi|$ are of high immediacy and generically define the bias and dispersion between the compared quantities, respectively. They, however, may not be suitable for consistently reporting statistical differences for data sets referring to very different ranges of the compared quantity, like those characterizing $L_{\mathrm{WN}}$ from different water types. Because of this, the root mean square of differences (RMSD) and the determination coefficient $r^{2}$ are also provided as a further aid for the comparison analysis.

The MODIS and VIIRS remote sensing products utilized for match-up construction have been obtained from the average of the $3 \times 3$ pixel values centered at the measurement site. These averages have been retained when (i) none of the 9 pixels is affected by the standard flags of the SeaDAS processing code (Bailey and Werdell, 2006) mainly indicating cloud or sun glint contaminations; (ii) the viewing and sun zenith angles are lower than 60 and $70^{\circ}$, respectively; (iii) the coefficient of variation (ratio of the standard deviation to the mean) of $L_{\mathrm{WN}}$ at $547 \mathrm{~nm}$ for MODIS or at $551 \mathrm{~nm}$ for VIIRS, from the $3 \times 3$ image elements centered at the measurement site, is lower than a threshold $\xi_{\mathrm{L}}$ to exclude data affected by a high spatial variability around the sampling point; and (iv) the difference between in situ and satellite data sampling time is lower than a threshold $\Delta_{t}$ to exclude matching data potentially affected by significant changes in measurement conditions with time.

The need to have high-quality data and additionally a statistically significant number of pairs may lead to conflicting criteria for the construction of a match-up set. Specifically, while a low $\xi_{\mathrm{L}}$ and a narrow $\Delta_{\mathrm{t}}$ are expected to satisfy greater quality needs, high $\xi_{\mathrm{L}}$ and wide $\Delta_{\mathrm{t}}$ are often required to produce a significant number of match-ups.

Based on previous investigations (Zibordi et al., 2009a), the current match-up analysis has been performed by setting $\xi_{\mathrm{L}} \leq 0.2$ and $\Delta_{\mathrm{t}} \leq \pm 2 \mathrm{~h}$. An assessment of the appropriateness of the selected thresholds for the GLR site has been performed by applying the stricter conditions $\xi_{\mathrm{L}} \leq 0.1$ and $\Delta_{\mathrm{t}} \leq \pm 1 \mathrm{~h}$. With reference to the values presented in Sect. 3.5, results from the analysis of MODIS-A relying on $L_{\mathrm{WN}}$ match-up values at $547 \mathrm{~nm}$ have shown a decrease of $16 \%$ (i.e., from 127 to 106) in the number of match-ups and only a slight change of $0.1 \%$ in the value of both $|\psi|$ and $\psi$. The equivalent exercise performed using VIIRS $L_{\mathrm{WN}}$ matchups values at $551 \mathrm{~nm}$ has shown a decrease of $37 \%$ (i.e., from 82 to 52) in the number of match-ups and changes of 0.1 and $1 \%$ (i.e., from -7 to $-8 \%$ ) in the value of $|\psi|$ and 

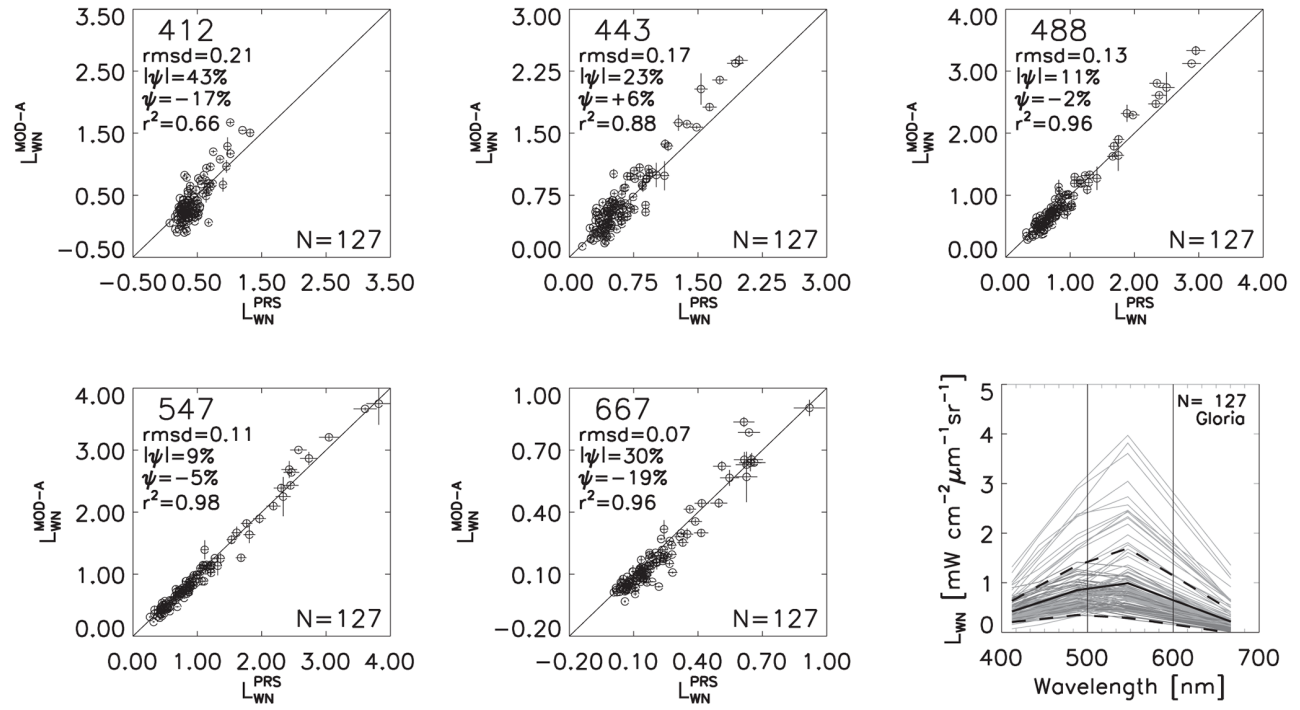

Figure 4. Scatterplots of MODIS-A (MOD-A) versus AERONET-OC (PRS) $L_{\mathrm{WN}}$ match-up values at selected center wavelengths for the GLR site. $N$ indicates the number of match-ups, $L \mathrm{WN}$ and RMSD are in units of $\mathrm{mW} \mathrm{cm}{ }^{-2} \mu \mathrm{m}^{-1} \mathrm{sr}^{-1}$, and $|\psi|$ is the mean of absolute percent differences, while $\psi$ is the mean of percent differences, and $r^{2}$ is the determination coefficient. The right panel in the second row displays the AERONET-OC $L_{\mathrm{WN}}$ spectra utilized to construct match-ups.
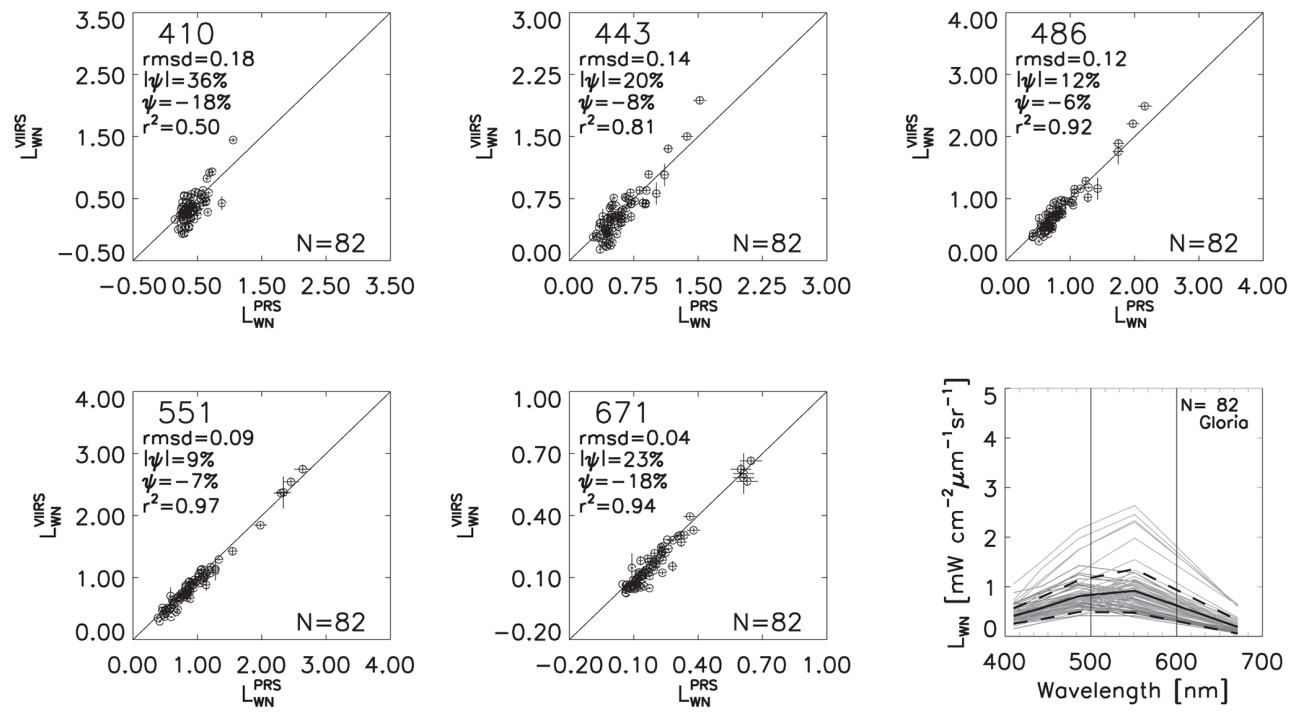

Figure 5. As in Fig. 4 but for VIIRS match-ups at GLR.

$\psi$, respectively, thus confirming the general suitability of the selected values $\xi_{\mathrm{L}} \leq 0.2$ and $\Delta_{\mathrm{t}} \leq \pm 2 \mathrm{~h}$ for match-up analysis at GLR. The same criteria have also been applied for the construction of AAOT match-ups.

\subsection{Results from $L_{\mathrm{WN}}$ match-ups}

The scatterplots of satellite (MODIS-A and VIIRS) versus in situ GLR match-up data are displayed in Figs. 4 and 5. Results exhibit values of $|\psi|$ decreasing from the blue toward the green and increasing again at the red center wavelengths.
MODIS-A shows values of $\psi$ varying within -5 and $+6 \%$ for the center wavelengths at 443,488 and $547 \mathrm{~nm}$, which are relevant for the determination of $\mathrm{Chl} a$. For the equivalent center wavelengths, the values of $\psi$ for VIIRS match-ups vary from -6 to $-8 \%$.

Excluding data at $412 \mathrm{~nm}$, MODIS-A results are close to those presented with match-ups constructed with independent in situ radiometric data collected over a large portion of the western Shelf during successive BiOMaP oceanographic campaigns (Zibordi et al., 2011). The marked differences in $\psi$ observed at $412 \mathrm{~nm}$, i.e., $+10 \%$, determined with $\mathrm{BiOMaP}$ 

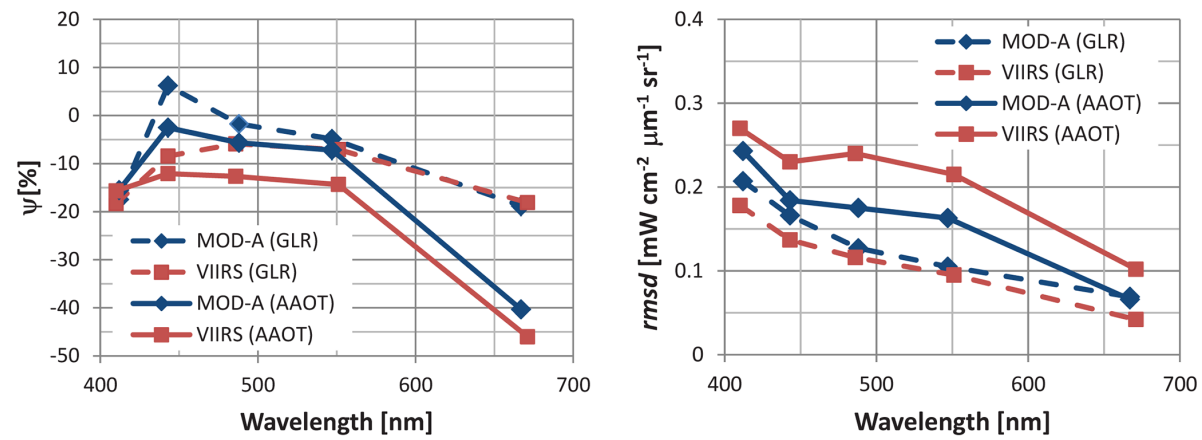

Figure 6. Values of $\psi$ (left panel) and RMSD (right panel) for MODIS-A and VIIRS match-ups for the GLR and AAOT sites.
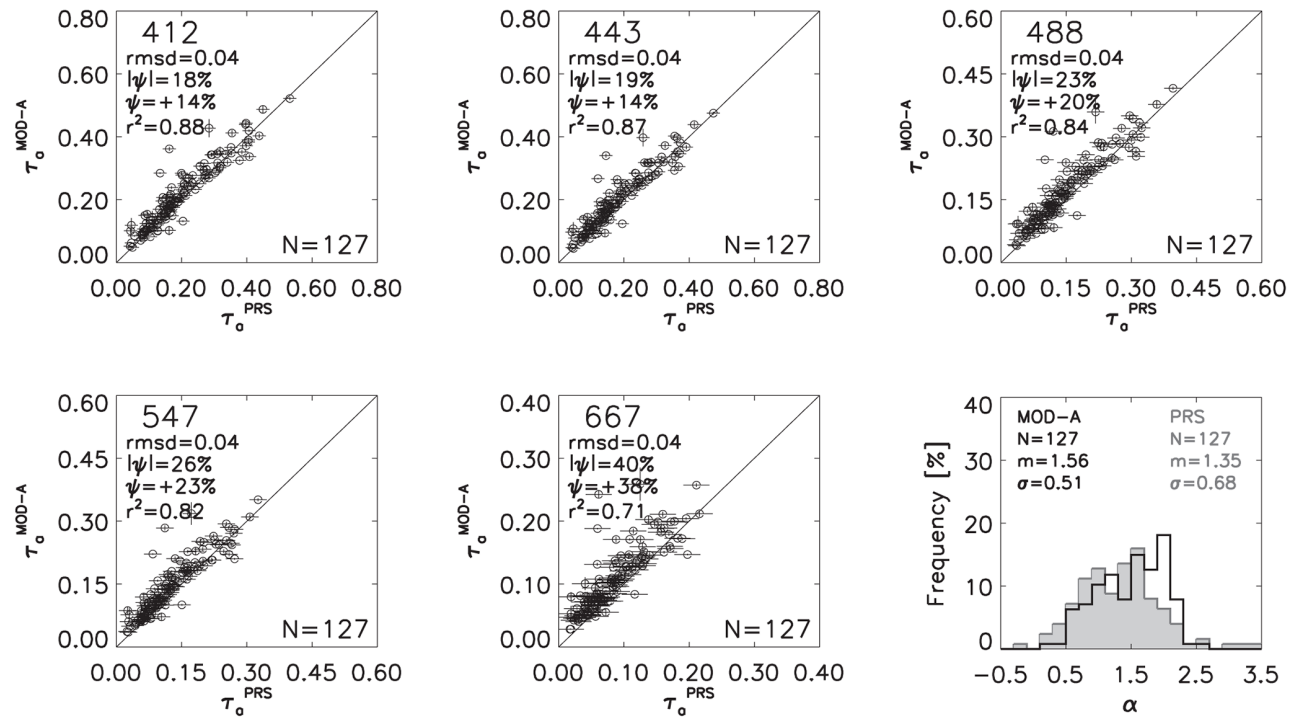

Figure 7. Scatterplot of MODIS-A (MOD-A) versus AERONET-OC (PRS) $\tau_{\mathrm{a}}$ at selected center wavelengths for the GLR site. $N$ indicates the number of match-ups, $\tau_{\mathrm{a}}$ and RMSD are dimensionless, and $|\psi|$ is the mean of absolute percent differences, while $\psi$ is the mean of percent differences, and $r^{2}$ is the determination coefficient. The right panel in the second row displays frequency distributions of $\alpha$ determined from $\tau_{\mathrm{a}}$ at 748 and $869 \mathrm{~nm}$ for MODIS-A, and 667 and $870 \mathrm{~nm}$ for PRS. The black characters and empty bars in the frequency distribution plot indicate results from the analysis of MODIS-A data, while the grey characters and the solid bars indicate results from the analysis of AERONET-OC data ( $m$ is the median and $\sigma$ the standard deviation).

data instead of the $-17 \%$ determined with GLR data, are likely due to large differences between in situ and satellite data for some match-ups in the lower range of values.

The intra-channel values of $\psi$ in Figs. 4 and 5 indicate that VIIRS systematically underestimates $L_{\mathrm{WN}}$ with respect to MODIS-A, as already reported in Hlaing et al. (2013) for a different reprocessing. However, the RMSD values are comparable or even slightly smaller for VIIRS (which, assuming identical absolute uncertainties, is in agreement with smaller mean spectral values of $\left.L_{\mathrm{WN}}\right)$. These findings suggest caution in focusing cross-mission comparisons on the sole analysis of relative uncertainties whose results may be largely conditioned by the range of values, the number of samples and their distribution.
In agreement with results from GLR, the statistical analysis from AAOT data more markedly confirms that VIIRS systematically underestimates $L_{\mathrm{WN}}$ with respect to MODISA. In particular, the values of $\psi$ for MODIS-A displayed in Fig. 6 (left panel) for the AAOT vary from -3 to $-7 \%$ at the center wavelengths of interest for the determination of Chl $a$. The corresponding values for VIIRS vary from -12 to $-14 \%$. The large $\psi$ values observed between 443 and $551 \mathrm{~nm}$ for VIIRS at the AAOT site may suggest difficulties with the atmospheric correction process more pronounced at the Adriatic Sea site and likely due to a less accurate determination of the aerosol type. It is noted that the large $\psi$ determined at 667 and $671 \mathrm{~nm}$ for both MODIS-A and VIIRS at the AAOT are explained by the very low values of $L_{\mathrm{WN}}$ characterizing the site and making questionable 
Table 2. Results from the analysis of satellite (SAT) and AERONET-OC (PRS) $\tau_{\mathrm{a}}$ match-ups at $869 \mathrm{~nm}$ for MODIS-A or $862 \mathrm{~nm}$ for VIIRS, at the GLR and AAOT sites. $N$ indicates the number of match-ups, RMSD is the root mean of squared differences, and $|\psi|$ is the mean of absolute percent differences, while $\psi$ is the mean of percent differences, and $r^{2}$ is the determination coefficient. The symbols $m^{\text {SAT }}, m^{\text {PRS }}$, $\sigma^{\mathrm{SAT}}$ and $\sigma^{\mathrm{PRS}}$ indicate the median and standard deviation, respectively, of the $\alpha$ values determined for satellite data (i.e., SAT) with $\tau_{\mathrm{a}}$ at 443 and $869 \mathrm{~nm}$ for MODIS-A, with $\tau_{\mathrm{a}}$ from 443 to $862 \mathrm{~nm}$ for VIIRS, and at equivalent wavelengths for AERONET-OC data (i.e., PRS).

\begin{tabular}{lccccccc}
\hline & $N$ & RMSD & $|\psi|$ & $\psi$ & $r^{2}$ & $m^{\text {SAT }}\left(\sigma^{\text {SAT }}\right)$ & $m^{\text {PRS }}\left(\sigma^{\text {PRS }}\right)$ \\
\hline MODIS-A at GLR & 127 & 0.03 & 48 & +40 & 0.50 & $1.58(0.41)$ & $1.60(0.32)$ \\
MODIS-A at AAOT & 759 & 0.03 & 43 & +33 & 0.57 & $1.61(0.40)$ & $1.55(0.39)$ \\
VIIRS at GLR & 82 & 0.04 & 67 & +62 & 0.63 & $1.31(0.36)$ & $1.58(0.41)$ \\
VIIR at AAOT & 109 & 0.03 & 44 & +34 & 0.72 & $1.41(0.33)$ & $1.44(0.39)$ \\
\hline
\end{tabular}

the results from the statistical analysis. In agreement with the values of $\psi$, the RMSD values for AAOT match-ups are also significantly larger for VIIRS than for MODIS-A (see Fig. 6, right panel). Finally, spectral differences of approximately $0.1 \mathrm{~mW} \mathrm{~cm}{ }^{-2} \mu \mathrm{m}^{-1} \mathrm{sr}^{-1}$ clearly characterize the shape of RMSD determined for the AAOT site with respect to GLR for both VIIRS and MODIS-A at 488 and $547 \mathrm{~nm}$ (or equivalent center wavelengths). These spectral variations are likely explained by different mean shapes and amplitudes of the $L_{\mathrm{WN}}$ spectra.

\subsection{Results from $\tau_{\mathrm{a}}$ match-ups}

AERONET-OC offers the unique opportunity to produce values of $\tau_{\mathrm{a}}$ at offshore sites likely not contaminated by land sources, and this creates almost ideal conditions for the validation of marine aerosol products. Figure 7 shows MODISA validation results for $\tau_{\mathrm{a}}$ at GLR obtained using in situ data band-shifted in agreement with the scheme detailed in $\mathrm{Zi}$ bordi et al. (2009a). These results exhibit spectrally constant RMSD values of 0.04 , while the bias expressed through $\psi$ increases with wavelength from $+14 \%$ at $412 \mathrm{~nm}$ to $+38 \%$ at $667 \mathrm{~nm}$. Comparisons of the Ångström exponent, $\alpha$, which provides the spectral dependence for $\tau_{\mathrm{a}}$, are shown in the last panel of Fig. 7. The values of $\alpha$, determined at 748 and $869 \mathrm{~nm}$ for MODIS-A and at the closest center wavelengths 667 and $870 \mathrm{~nm}$ for AERONET-OC data, indicate a slight overestimate for MODIS-A, with a median value of 1.56 versus 1.35 determined from in situ data.

Equivalent validation results for $\tau_{\mathrm{a}}$ at the AAOT (not shown, being already the matter of previous independent analysis; see Zibordi et al., 2013; Mélin et al., 2013) exhibit RMSD decreasing from 0.05 at $412 \mathrm{~nm}$ to 0.04 at $667 \mathrm{~nm}$, and values of $\psi$ increasing from +21 to $+40 \%$ in the same spectral interval. Additionally, equivalent to GLR, the values of $\alpha$ from MODIS-A at the AAOT exhibit an overestimate with respect to those determined from AERONET-OC data (i.e., 1.61 versus 1.36 ). These overestimates are consistent, even though more pronounced, with respect to those described in Mélin et al. (2013).

Results from the analysis of $\tau_{\mathrm{a}}$ in the near-infrared and of $\alpha$ across the spectral range of interest (different from the $\alpha$ values plotted in Fig. 7 restricted to the red and near-infrared spectral region) are summarized in Table 2. These results indicate large overestimates for both MODIS-A and VIIRS $\tau_{\mathrm{a}}$ in the near-infrared at GLR (i.e., +40 and $+62 \%$, respectively) and at AAOT ( +33 and $+34 \%$, respectively), with values of RMSD of 0.03 for both satellite sensors and both sites. The agreement between satellite and in situ determinations of $\alpha$ is quite high, with the exception of VIIRS matchups at GLR, which show underestimated values for VIIRS, with a median of 1.31 with respect to 1.58 determined from AERONET-OC data. These latter values may suggest a different performance of VIIRS atmospheric correction at the GLR and AAOT sites that may explain the appreciable differences highlighted by the statistical analysis of $L_{\mathrm{WN}}$ matchups (see Fig. 6).

\subsection{Intra-annual climatology at the GLR and AAOT sites}

Considering the relevance of satellite ocean color data for climatological studies in optically complex coastal waters, the intra-annual climatology of the $L_{\mathrm{WN}}(547) / L_{\mathrm{WN}}(488)$ ratio for MODIS-A or $L_{\mathrm{WN}}(551) / L_{\mathrm{WN}}(486)$ for VIIRS data has been investigated at the GLR site using AERONET-OC for comparison. Specifically, Fig. 8 has been constructed using all available data at the time of the analysis. Recalling that, among other optically significant constituents, the proposed spectral ratio is largely related to Chl $a$ being $L_{\mathrm{WN}}(\lambda)$ linked to $R_{\mathrm{rs}}(\lambda)$ applied for its quantification (see Eq. 3), the annual climatology obtained from the three different data sources exhibits a significant qualitative agreement despite differences in the number of data and the few years used for the analysis. Specifically, regardless of the large variability of the spectral ratio explained by the expected large inter-annual differences (McQuatters-Gollop et al., 2008), the time series exhibit an extended maximum in winter increasing toward spring. Secondary maxima occur from late spring and in fall. The succession of maxima can be explained by the specific location of GLR in a region influenced by two seasonal cycles, i.e., that typical of the Shelf and of the open sea (see Sect. 2). 

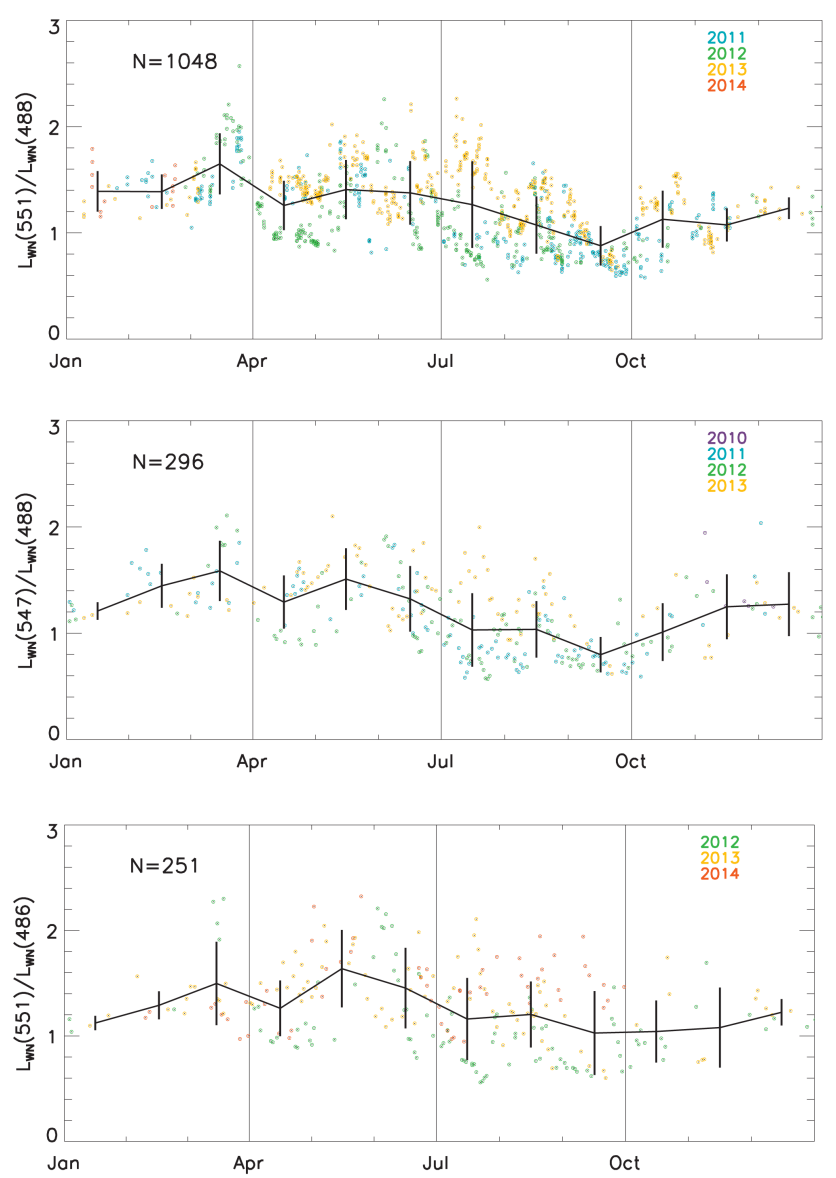

Figure 8. Annual climatology at GLR for the ratios $L_{\mathrm{WN}}(551) / L_{\mathrm{WN}}(488)$ for AERONET-OC (upper panel), $L_{\mathrm{WN}}(547) / L_{\mathrm{WN}}(488)$ for MODIS-A (central panel) data, and $L_{\mathrm{WN}}(551) / L_{\mathrm{WN}}(486)$ for VIIRS (lower panel), determined with all available data for the period 2010-2014. The thick black line indicates monthly averages, while vertical bars indicate \pm 1 standard deviation. $N$ is the number of data.

Overall results provide confidence in climatological applications of MODIS-A and VIIRS data in the Black Sea optically complex waters. The analysis also highlights the suitability of AERONET-OC data for exploring bio-optical processes by relying on data collected on a small spatial scale.

\section{Discussion and conclusions}

This work has addressed the applicability of an AERONETOC site located in the Western Black Sea (i.e., GLR) for the continuous validation of satellite ocean color primary data products (i.e., $L_{\mathrm{WN}}$ and $\tau_{\mathrm{a}}$ ). The analysis has been conducted including data from the AERONET-OC site in the northern Adriatic Sea (i.e., AAOT) often exhibiting water types similar to those observed at GLR.

Results from the assessment of $L_{\mathrm{WN}}$ satellite data products at both GLR and AAOT indicate mean relative differ- ences $\psi$ with respect to in situ data at the center wavelengths 443,488 and $547 \mathrm{~nm}$ (or equivalent), varying between -5 and $+6 \%$ for MODIS-A and from -6 to $-8 \%$ for VIIRS. These reasonable percent differences at the center wavelengths commonly applied for the determination of Chl $a$ are overwhelmed by negative values of $\psi$ in the range of 15$20 \%$ at $412 \mathrm{~nm}$ and between 20 and $45 \%$ in the red, quantified for both VIIRS and MODIS-A. Cross-mission intercomparisons based on both GLR and AAOT AERONET-OC data suggest a systematic underestimate (more pronounced at the AAOT site) of $L_{\mathrm{WN}}$ data for VIIRS with respect to MODIS-A.

The analysis of MODIS-A $\tau_{\mathrm{a}}$ satellite-derived data at GLR indicates an increase in $\psi$ from $+14 \%$ at $412 \mathrm{~nm}$ to $+38 \%$ at $667 \mathrm{~nm}$, with a spectrally constant RMSD of 0.04 . The analysis of $\tau_{\mathrm{a}}$ in the near-infrared indicates large overestimates for both MODIS-A and VIIRS $\tau_{\mathrm{a}}$ (i.e., +40 and $+62 \%$, respectively) at GLR and ( +33 and $+32 \%$, respectively) at AAOT, with values of RMSD of 0.03 for both satellite sensors and both sites. The good agreement between satellite and in situ determinations of $\alpha$ in the full spectral region of interest exhibits an exception for VIIRS match-ups at GLR, which show underestimated values for VIIRS with a median of 1.31 with respect to the 1.58 determined from AERONETOC data. This result suggests different performances of the VIIRS atmospheric correction at the GLR and AAOT sites.

An interesting feature is offered by the annual climatology of $L_{\mathrm{WN}}$ spectral ratios (i.e., $L_{\mathrm{WN}}(547) / L_{\mathrm{WN}}(488)$, or equivalent) at the GLR site. Specifically, both in situ and satellitederived data indicate general trends confirming the existence of two different bio-optical regimes, one typical of the open Black Sea, with high Chl $a$ values occurring in winter and increasing during early spring, and the other common for the Shelf region, exhibiting maxima from late spring and in fall.

The notable high values of $\psi$ determined from the analysis of in situ and satellite match-ups of $L_{\mathrm{WN}}$ may create concerns, especially when considering the $5 \%$ maximum uncertainty target usually included among the objectives of most satellite ocean color missions. However, it must be recognized that such a target commonly refers to oceanic oligotrophic and mesotrophic $\mathrm{Chl} a$-dominated waters. In the case of coastal regions, uncertainties associated with $L_{\mathrm{WN}}$ tend to increase as the atmospheric correction process is challenged by local conditions. Additionally, the decrease in the $L_{\mathrm{WN}}$ values toward the blue, due to an increase in absorption by water constituents with respect to oligotrophic and mesotrophic $\mathrm{Chl} a$-dominated waters, amplifies the relative differences while assuming identical absolute differences. This suggests that when addressing differences between satellite and in situ data, aside from statistical indices providing relative values (i.e., in \%) of immediate interpretation, it is important to add indices related to absolute differences.

It is finally underlined that the present work proposes new regional bio-optical algorithms for the Western Black Sea 
applicable for the determination of a number of bio-optical quantities (i.e., Chl $a, a_{\mathrm{ph}}, a_{\mathrm{dp}}, a_{y}$ ) and for corrections minimizing the effect of differences in center wavelengths between diverse sources of radiometric data (e.g., in situ and satellite).

Acknowledgements. The authors wish to thank NASA OBPG for granting access to the MODIS and VIIRS data. Additional acknowledgments are due to the NASA AERONET-OC team for the effort placed in maintaining the network infrastructure. Acknowledgments are also due to the personnel of the Grigore Antipa National Institute for Marine Research and Development in Constanta and to the Petrom oil company, for the continuous support in maintaining the GLR site. Lastly, unconditional gratitude is expressed to the many scientists and friends who contributed to the logistic, laboratory and field activities essential for the creation of the Black Sea data set included in BiOMaP with support from the North Atlantic Treaty Organization under contract no. 982678 (Science for Peace Project), the European Union Seventh Framework Programme under grant agreement no. 228344 (EUROFLEETS), the Joint Research Centre, the Romanian Space Agency and the European Space Agency.

Edited by: O. Zielinski

\section{References}

Bailey, S. W. and Werdell, P. J.: A multi-sensor approach for the on-orbit validation of ocean color satellite data products, Rem. Sens. Environ., 102, 12-23, 2006.

Behrenfeld, M. J., O’Malley, R. T., Siegel, D. A., McClain, C. R., Sarmiento, J. L., Feldman, G. C., Milligan, A. J., Falkowski, P. G., Letelier, R. M., and Boss, E. S.: Climate-driven trends in contemporary ocean productivity, Nature, 444, 752-755, 2006.

Berthon, J.-F., Mélin, F., and Zibordi, G.: Ocean Colour Remote Sensing of the Optically Complex European Seas, in: Remote Sensing of the European Seas, edited by: Barale, V. and Gade, M., Springer, Dordrecht (NL), pp. 35-52, 2008.

D'Alimonte, D., Zibordi, G., Berthon, J. F., Canuti, E., and Kajiyama, T.: Performance and applicability of bio-optical algorithms in different European seas, Rem. Sens. Environ., 124, 402-412, 2012.

D'Alimonte, D., Zibordi, G., Kajiyama, T., and Berthon, J.-F.: Comparison between MERIS and regional high-level products in European seas, Rem. Sens. Environ., 140, 378-395, 2014.

Eck, T. F., Holben, B. N., Reid, J. S., Dubovik, O., Smirnov, A., O'Neill, N. T., Slutsker, I., and Kinne, S.: Wavelength dependence of the optical depth of biomass burning, urban and desert dust aerosols, J. Geophys. Res., 104, 31333-31350, 1999.

Field, C. B., Behrenfeld, M. J., Randerson, J. T., and Falkowski, P.: Primary production of the biosphere: integrating terrestrial and oceanic components, Science, 281, 237-240, 1998.

Fu, G., Baith, K., and McClain, C.: The SeaWiFS Data Analysis System, Proceedings of the 4th Pacific Ocean Remote Sensing Conference, Quigdao, China, pp. 73-79, 1998.

Gergely, M. and Zibordi, G.: Assessment of AERONET $L_{\mathrm{WN}}$ uncertainties, Metrologia, 51, 40-47, 2014.
Gordon, H. R. and Wang, M.: Retrieval of water-leaving radiance and aerosol optical thickness over the oceans with SeaWiFS: a preliminary algorithm, Appl. Optics, 33, 443-452, 1994.

Hlaing, S., Harmel, T., Gilerson, A., Foster, R., Weidemann, A., Arnone, R., Wang, M., and Ahmed, S.: Evaluation of the VIIRS ocean color monitoring performance in coastal regions, Rem. Sens. Environ., 139, 398-414, 2013.

Holben, B. N., Eck, T. F., Slutsker, I., Tanré, D., Buis, J. P., Setzer, A., Vermote, E., Reagan, J. A., Kaufman, Y. J., Nakajima, T., Lavenu, F., Jankowiak, I., and Smirnov, A.: AERONET - A federated instrument network and data archive for aerosol characterization, Rem. Sens. Environ., 66, 1-16, 1998.

Jolliffe, I.: Principal component analysis, John Wiley \& Sons, Ltd., New York, 2002.

Kideys, A. E.: Fall and rise of the Black Sea ecosystem, Science, 297, 1482-1484, 2002

Kirk, J. T. O.: Spectral absorption properties of natural waters: Contribution of the soluble and particulate fractions of light absorption in some inland waters of south-eastern Australia, Aust. J. Mar. Fresh. Res., 31, 287-296, 1980.

Kopelevich, O. V., Burenkov, V. I., Ershova, S. V., Sheberstov, S. V., and Evdoshenko, M. A.: Application of SeaWiFS data for studying variability of bio-optical characteristics in the Barents, Black and Caspian Seas, Deep Sea Res. Part II: Topical Studies in Oceanography, 51, 1063-1091, 2004.

Lohrenz, S. E. and Cai, W.-J.: Satellite ocean color assessment of air-sea fluxes of $\mathrm{CO} 2$ in a river-dominated coastal margin, Geophys. Res. Lett., 33, L01601, doi:10.1029/2005GL023942, 2006.

Longhurst, A., Sathyendranath, S., Platt, T., and Caverhill, C.: An estimate of global primary production in the ocean from satellite radiometer data, J. Plankton Res., 17, 1245-1271, 1995.

McQuatters-Gollop, A., Mee, L. D., Raitsos, D. E., and Shapiro, G. I.: Non-linearities, regime shifts and recovery: The recent influence of climate on Black Sea chlorophyll, J. Marine Syst., 74, 649-658, 2008.

Mélin, F. and Zibordi, G.: Optically based technique for producing merged spectra of water-leaving radiances from ocean color remote sensing, Appl. Optics, 46, 3856-3869, 2007.

Mélin, F., Zibordi, G., Carlund, T., Holben, B. N., and Stefan, S.: Validation of SeaWiFS and MODIS Aqua-Terra aerosol products in coastal regions of European marginal seas, Oceanologia, 55, 25-71, 2013.

Morel, A. and Maritorena, S.: Bio-optical properties of oceanic waters: A reappraisal, J. Geophys. Res., 106, 7163-7180, 2001.

Morel, A., Antoine, D., and Gentili, B.: Bidirectional reflectance of oceanic waters: accounting for Raman emission and varying particle scattering phase function, Appl. Optics, 41, 6289-6306, 2002.

Oguz, T.: Anthropogenic Forcing, Oceanography, 18, 112-121, 2005.

Platt, T., Fuentes-Yaco, C., and Frank, K. T.: Marine ecology: spring algal bloom and larval fish survival, Nature, 423, 398-399, 2003.

Prieur, L. and Sathyendranath, S.: An optical classification of coastal and oceanic waters based on the specific spectral absorption curves of phytoplankton pigments, dissolved organic matter, and other particulate materials, Limnol. Oceanogr., 46, 11301140, 1981. 
Sancak, S., Besiktepe, S. T., Yilmaz, A., Lee, M., and Frouin, R.: Evaluation of SeaWiFS chlorophyll-a in the Black and Mediterranean Seas, Int. J. Rem. Sens., 26, 2045-2060, 2005.

Smirnov, A., Holben, B. N., Eck, T. F., Dubovik, O., and Slutsker, I.: Cloud screening and quality control algorithms for the AERONET database, Rem. Sens. Environ., 73, 337-349, 2000.

Sorokin, Y. A.: The Black Sea: ecology and oceanography. Biology of Inland Waters, Backhuys, Leiden, the Netherlands, 875 pp., 2002.

Stumpf, R. P.: Applications of satellite ocean color sensors for monitoring and predicting harmful algal blooms, Hum. Ecol. Risk Assess., 7, 1363-1368, 2001.

Thuillier, G., Hersé, M., Labs, D., Foujols, T., Peetermans, W., Gillotay, D., Simon, P. C., and Mandel, H.: The solar spectral irradiance from 200 to $2400 \mathrm{~nm}$ as measured by the SOLSPEC spectrometer from the Atlas and Eureca missions, Solar Phys., 214, 1-22, 2003.

Vinogradov, M., Shushkina, E., Mikaelyan, A., and Nezlin, N. P.: Temporal (seasonal and interannual) changes of ecosystem of the openwaters of the Black Sea, in: Environmental Degradation of the Black Sea: Challenges and Remedies, edited by: Besiktepe, S. T., Unlüata, U., and Bologa, A. S., Kluwer Academic Publishers, Dordrecht, 109-129, 1999.

Wang, M., Knobelspiesse, K. D., and McClain, C. R.: Study of the Sea-viewing Wide Field-of-View Sensor (SeaWiFS) aerosol optical property data over ocean in combination with the ocean color products, J. Geophys. Res., 110, D10S06, doi:10.1029/2004JD004950, 2005.
Ware, D. M. and Thompson, R. E.: Bottom-up ecosystem trophic dynamics determine fish production in the Northeast Pacific, Science, 308, 1280-1284, 2005.

Yentsch, C. S.: Measurement of the visible light absorption by particulate matter in the ocean, Limnol. Oceanogr., 7, 207-217, 1962.

Zibordi, G., Mélin, F., and Berthon, J.-F.: Comparison of SeaWiFS, MODIS and MERIS radiometric products at a coastal site, Geophys. Res. Lett., 33, L06617, doi:10.1029/2006GL025778, 2006.

Zibordi, G., Berthon, J. F., Mélin, F., D’Alimonte, D., and Kaitala, S.: Validation of satellite ocean color primary products at optically complex coastal sites: Northern Adriatic Sea, Northern Baltic Proper and Gulf of Finland, Rem. Sens. Environ., 113, 2574-2591, 2009a.

Zibordi, G., Holben, B., Slutsker, I., Giles, D., D’Alimonte, D., Mélin, F., Berthon, J.-F., Vandemark, D., Feng, H., Schuster, G., Fabbri, B. E., Kaitala, S., and Seppälä, J.: AERONET-OC: a network for the validation of Ocean Color primary radiometric products, J. Atmos. Oceanic Technol., 26, 1634-1651, 2009b.

Zibordi, G., Berthon, J.-F., Mélin, F., and D'Alimonte, D.: Crosssite consistent in situ measurements for satellite ocean color applications: the BiOMaP radiometric dataset, Rem. Sens. Environ., 115, 2104-2115, 2011.

Zibordi, G., Mélin, F., Berthon, J.-F., and Canuti, E.: Assessment of MERIS ocean color data products for European seas, Ocean Sci., 9, 521-533, doi:10.5194/os-9-521-2013, 2013. 